\title{
Communal Prejudice as Related To Paranormal Beliefs
}

\section{among Adolescence}

\author{
Kehksha $^{1}$, Nancy Agrawal ${ }^{1}$
}

\section{ABSTRACT}

The present study is an effort to explore communal Prejudice as Related to Paranormal Beliefs among Adolescence boys. The sample of the study consists of 80 subjects and the tools used were: communal prejudice scale and paranormal belief. We applied Pearson Product Moment correlation for the analysis of data. The results expose the positive correlation between communal prejudice and paranormal beliefs. On the basis of result, we can state that communal prejudice and paranormal beliefs are interrelated. It means if paranormal beliefs increase the communal prejudice will also increase and vice versa. In this study we found positive but slight relationship between these two variables that is communal prejudice \& paranormal beliefs.

Keywords: Communal prejudice, paranormal beliefs, Adolescents.

WHO identifies adolescence as the period in human growth and development that occurs after childhood and before adulthood, from ages 10 to19. Nurmi (2001) defined adolescence as a distinct period of adjustment or as a journey to adulthood and this is the stage where a teenager has to face rapid physical, cognitive and social changes (Nurmi 1997). Adolescents spent a major part of their time at school, in family and with the company of peers for developing social and psychological calibers. School environment and interrelation with the people at school and surroundings influence the learning and cognition of adolescence. The transitional period raises various issues related to self-identity and independence in their mind. Most of the adolescence has to take hard decisions in their life regarding stream of education, schoolwork, sexual relation, smoking, their social life etc. to run their life smoothly. They interact and observe others and learn from their surroundings. Sometimes their dependency distorts their approach that can lead them to be prejudiced.

\section{Paranormal beliefs}

Broad (1949) and Tobayck (1995) explained the term paranormal to describe phenomena, which if authentic, violate basic limiting principles of science. Paranormal beliefs are the phenomenon that is predominant in any society, country or culture. These believe and faiths can't be explained

\footnotetext{
${ }^{1}$ Department of Psychology, Aligarh Muslim University

(C) 2015 I Kejksha, N Agrawal; licensee IJIP. This is an Open Access Research distributed under the terms of the Creative Commons Attribution License (http://creativecommons.org/licenses/by/2.0), which permits unrestricted use, distribution, and reproduction in any Medium, provided the original work is properly cited.
} 
scientifically. Description of such believes are beyond normal experience. Stenger and Victor (1990) specified paranormal phenomenon as different from hypothetical concepts such as dark matter and dark energy. Unlike paranormal phenomena, these hypothetical concepts are based on empirical observations and experimental data gained through the scientific method. There are numerous forms of paranormal belief.Gordon and Stuart (1993) explicated the most common paranormal believe of human life as ghosts, extra-terrestrial life, unidentified flying objects, psychic abilities or extrasensory perception and cryptids. These types of objects influence significantly the personality as well as behavior (Lester, 1994; So sis, Strickland, \& Haley, 1980).Various factors such as family, peer group, media and society influence individuals heavily. Besides this, culture, tradition, social and religious organizations e.g. the churches (Schriever, 2000) are also collaborate in altering the stage of human mind.

Lester, Thinschmidt and Trautman (1987) explored a fact in their study that precognition experience and paranormal belief both have a direct relation with feeling and intuition scores. Through this study they disclosed an interesting view that such types of believers are open minded but they are irrational. They prefer to live in the fantasy mare than nonbelievers.

\section{Prejudice}

Prejudice generally refers to negative attitudes or response that is directed towards social outgroups. As an attitude, prejudice is the negative feelings experienced on the part of the prejudiced when they are in the presence of, or merely think about, members of the groups they dislike (Brewer and Brown 1998). These negative attitudes solely based on the membership of that individual in the particular group. Prejudice forces the individual to act often with a discriminatory approach towards members of these groups but the expression of such overt or covert discrimination depends on the norms and acceptance of doing such attitude in the culture (Crandall et al, 2002., Jetten, Spears and Manstead, 1997., Turner et al., 1987). However there is not enough research on prejudice that can determine the cause of development of prejudice among children and adults. Adolescence's prejudice about their society and peers can affect their outcome.

\section{SIGNIFICANCE OF THE STUDY}

Despite the fact that adolescence may be an important age for prejudice development, relatively little research has focused on this age group. Moreover, most research on the development of prejudice comes either from a cognitive developmental perspective or from non-developmental social psychological theories regarding adults applied to children and adolescents. Thus, little is known about the paranormal beliefs important to prejudice during adolescence.

\section{OBJECTIVE OF THE STUDY}

The main objective of the current study is to find out the relation between communal prejudice and paranormal beliefs among adolescence boys getting education in madrasa. 


\section{HYPOTHESIS}

For the present research study, we have conducted null hypothesis. Therefore we assumed that there is no relationship between communal prejudice and paranormal beliefs.

\section{METHODOLOGY}

Sample and sampling design - for conducting the present research study and measuring the correlation between communal prejudice and paranormal beliefs, a sample consists of 80 adolescence boys were selected. The age of the sample ranged from 15 to 19. All the subjects were selected randomly from the madrasa of Aligarh.

\section{Tool for the research}

Prejudice scale- Prejudice scale introduced by QamarJahan, Bharadwaj and Saeeduzzafar in (1986) was applied to measure the prejudice among adolescence. The total items in this scale are 32 which show the prejudice level of subjects. It is a seven point scale. Minimum score of this scale is 32 and highest score is 160 . This scale contains satisfactory reliability and validity.

Revised Paranormal Belief Scale (RPBS) - For measuring Paranormal Belief, we applied Revised Paranormal Belief Scale (RPBS) of Tobayck (1988). It contains 26 items. This scale provides a measure of degree of belief in each of seven dimensions: Traditional Religious Belief, Psi, Witchcraft, Superstition, Spiritualism, Extraordinary Life Forms, and Precognition. It is a seven-point rating scale. Score of this scale ranges from 26 to 182. The cronbach alpha coefficient of this scale is 0.91 .

\section{Procedure}

For conducting research, we approached the students of madrasa through the head of the institutions for the purpose of getting data from them. Before collecting information, we established good rapport with them. We collected data from each student individually. We applied both the two scales on all of the students. We took them in confidence and instructed them to fill up the questionnaires as per the guide line printed on each questionnaire. We asked them to co-operate to do this work for academic purpose and they agreed to give information on the entire questionnaire. In this way we collected the data and scored for analysis.

\section{DATA ANALYSIS}

In the present study, we assessed communal prejudice and paranormal beliefs among adolescence. We analyzed the obtained data with the help of Karl- Pearson product moment coefficient of correlation to establish the relation between mentioned variables. Below the table, shows relation between communal prejudice and paranormal beliefs among adolescence. 
Table - Pearson product moment coefficient of correlation between communal prejudice and paranormal beliefs among adolescence

\begin{tabular}{|l|l|l|l|l|l|l|}
\hline Sample & Variable & N & df & r & Sig. & result \\
\hline Boys & communal prejudice & 80 & 78 & $.20 *$ & .001 & significant \\
\cline { 2 - 3 } & paranormal beliefs & & & & & \\
\hline
\end{tabular}

*Significant at 0.5 level

The present result reveals that that correlation value, established between communal prejudice and paranormal beliefs is $r=0.20$. The obtained value represents that there is significantly positive but slight correlation between both the variables. We found this value significant at 0.5 level. It means that increased level of paranormal beliefs helps in the development of prejudice and vice versa among adolescence madrasa boys. Though the obtained data shows slight relationship, it can be stated that paranormal beliefs are not wholly responsible for producing communal prejudice in them. There may be some other factors responsible for communal prejudice in madrasa adolescence boys.

\section{CONCLUSION}

The present research discloses the fact that increased level of paranormal beliefs leads the madrasa adolescence boys to be prejudiced. Therefore it is harmful for the adolescence to have strong paranormal beliefs as they become prejudiced. Michael Dambrun (2004) also explored in a study that paranormal belief that is belief in astrology become a significant predictor of prejudice for stigmatized group of people. His research supports the present study.

\section{REFERENCES}

Blackmore, S. J. (1994). Are women more sheepish? Gender differences in belief in the paranormal. In L. Coley and R. A. White (Eds.), Women and parapsychology. New York: Parapsychology Foundation.

Brewer, M. B., Brown, R. (1998). Intergroup relations. In D.T. Gilbert, S.T. Fiske and G. Lindzey (Eds.) The Handbook of Social Psychology, 4, vol. 2, 554-594. New York: McGraw-Hill.

Broad, C. D. (1949). The relevance of psychical research to philosophy. Philosophy, 24, 291309.

Crandell,C.S., Eshleman, A. and O’Brien, L.T.(2002) social norms and the expression and suppression of prejudice: the struggle for internalization. Journal of Personality and Social Psychology 82, 359-378.

Dambrun, M. (2004).Belief in paranormal determinism as a source of Prejudice toward disadvantaged groups: "the dark side of stars" Social Behavior and Personality, 32(7), 627-636.

Gordon, Stuart. (1993). The Paranormal: An Illustrated Encyclopedia. Trafalgar Square. ISBN 978-0747236030. 
Jetten, J., Spears, R., and Manstead, A.S.R. (1997). Strength of identification and intergroup differentiation: the influence of group norms. European Journal of Social Psychology, 27, 603-609.

Lester, D., Thinschmidt, J. \& Trautman, L. (1987). Paranormal belief and Jungian dimensions of personality. Psychological Reports, 61, 182.

Schriever, F. (2000). Are there different cognitive structures behind paranormal beliefs? European Journal of Parapsychology, 15, 46-47.

Stenger, Victor. (1990). Physics and Psychics: The Search for a World beyond the Senses. Prometheus Books. pp. 33-52. ISBN 978-0-87975-575-1.

Tobayck, J. J. (1995). Final thoughts on issues in the measurement of paranormal beliefs. The Journal of Parapsychology, 59, 141-145.

Turner, J.C., Hogg, M.A., Oakes, P. J., Reicher, S.D., and Wetherell, M.S. (1987). Rediscovering the social group: a self-categorization theory. Oxford U K: Blackwell. 